\section{Hyperosmolar Dehydration in Infancy Due to Faulty Feeding}

The infant is dependent upon its mother to interpret its dietary needs and though some degree of latitude can be allowed to meet the requirements of the individual in terms of quantity, the composition of the food should be carefully controlled.

A cry for thirst can easily be interpreted as a cry of hunger and a diligent mother may inadvertently satisfy this demand with more calories rather than more fluid.

We wish to report this case to emphasize the dangers of improperly constituted feeds.

\section{Case Report}

A 9-month-old girl was admitted to hospital with a 5-day history of fretting and reluctance to feed. For 2 days she had been vomiting 'black fluid' and had become progressively more drowsy. Between vomits mother had encouraged her to take small milk feeds. There was no accompanying diarrhoea.

The infant, the second of two children, had thrived and developed normally until this episode. Pregnancy had been normal and she was born at term weighing $3121 \mathrm{~g}$. She was fed on full cream powdered milk, and at the time of admission was receiving $227 \mathrm{~g}$ three times a day, each containing 6 to 7 very heaped scoops of powder and a teaspoon of sugar to $198 \mathrm{~g}$ of water, supplemented with one or two tins of baby foods daily. There was no added salt.

On admission the child was limp and unconscious, responding only to painful stimuli. She was pale and had cold extremities though her body temperature was $38.9^{\circ} \mathrm{C}$. Her pulse rate was 192 per minute and regular, but her blood pressure could not be recorded. She was clinically dehydrated and her abdomen felt 'doughy'. Her fundi and pupil reactions to light were normal, there was no nuchal rigidity or photophobia but she was severely hypotonic and had brisk reflexes.

Initial plasma electrolytes were $\mathrm{Na}+207 \mathrm{mEq} / 1$., $\mathrm{Cl}-166 \mathrm{mEq} / \mathrm{l} ., \mathrm{K} \div 4.7 \mathrm{mEq} / \mathrm{l} ., \mathrm{HCO}_{3}^{-} 23 \mathrm{mEq} / \mathrm{l}$, $\mathrm{Ca}++11 \mathrm{mg} / 100 \mathrm{ml}$, urea $396 \mathrm{mg} / 100 \mathrm{ml}$, glucose $138 \mathrm{mg} / 100 \mathrm{ml}, \mathrm{Hb} 15 \mathrm{~g} / 100 \mathrm{ml}$. Blood and CSF cultures were sterile. The plasma osmolality was 510 $\mathrm{mOsm} / \mathrm{kg}$.

A policy of very slow intravenous rehydration was instituted starting with isotonic saline and proceeding through progressively more dilute solutions to $0 \cdot 18 \%$ saline in $4.3 \%$ dextrose. Plasma electrolytes and osmolality returned to normal over the next 7 days (Fig.). During this period she passed 2 melaena stools and was transfused with $80 \mathrm{ml}$ of whole blood. At no time did she have convulsions.

By the 10th day she was fully rehydrated but remained markedly hypotonic and unresponsive to environmental stimuli. She developed transient choreoathetoid movements of her limbs, most pronounced in the digits.

By the third week she had returned to normal, except

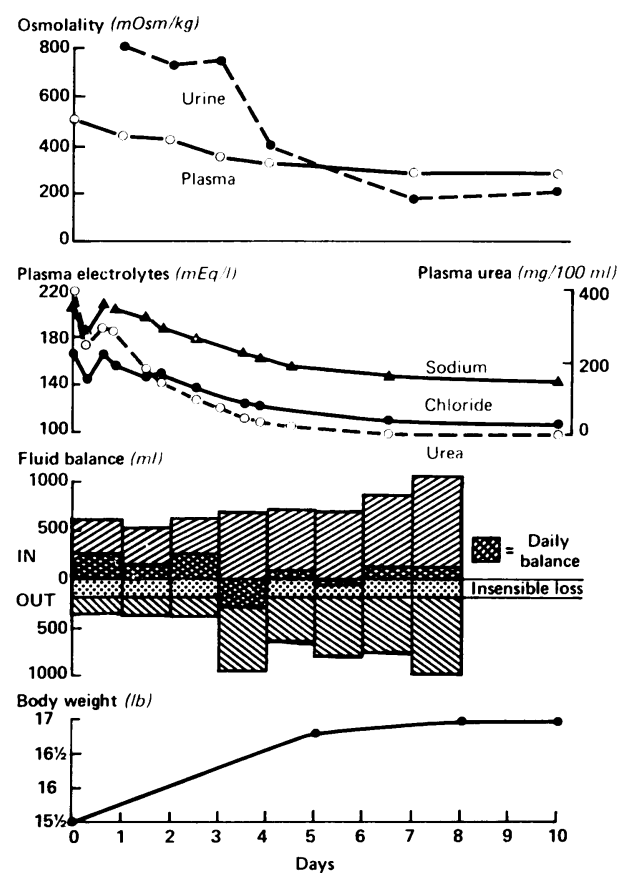

Fig.-Recovery period in which plasma osmolality, sodium, chloride, and urea levels returned to normal on a regimen of gradual rehydration as illustrated by the fluid

balance chart and weight gain during this period.

for reduced truncal tone and some unsteadiness of purposeful head and hand movements. An EEG at this time was within normal limits. By the fifth week there was no evidence of residual neurological damage, and she was developing normally.

\section{Discussion}

Inability of the infant to regulate its own dietary requirements, a higher rate of turnover of water (Darrow, 1959), and immature renal function make hyperosmolar (hypernatraemic) dehydration a commoner condition in childhood than in later life. It is usually due to disproportionate fluid losses in the diarrhoea and vomiting of acute gastroenteritis, but there is good evidence to show that high solute feeds, in themselves, may precipitate this dysfunction (Finberg and Harrison, 1955; Colle, Ayoub, and Raile, 1958; Cochrane, 1965; Skinner, 1967; Simpson and O'Duffy, 1967). The use of artificial milk feeds may explain its prevalence among technologically advanced cultures (Taitz, 1971), for infants fed on breast milk, a low solute feed, are not liable to develop this state.

Administration of a high protein, high solute load, which occurs when powdered or evaporated 
milk preparations are inadequately diluted, will tend to produce hypernatraemia and uraemia. The child may be able to compensate for a time but the extra fluid losses that will ensue if vomiting and an osmotic diuresis occur, or if fluid losses exceed intake as in increased sweating during a fever or bout of hot weather, will rapidly lead to hypernatraemic dehydration.

The importance in recognizing this condition in distinction to the commoner isonatraemic dehydration is the greater mortality and morbidity that accompanies it. Of children so affected, $8 \%$ die and $8 \%$ have residual brain damage (Macaulay and Watson, 1967). Morris-Jones, Houston, and Evans (1967) have shown that $71 \%$ of cases with plasma $\mathrm{Na}^{+}$greater than $158 \mathrm{mEq} / 1$. have convulsions often during the period of recovery. $87 \%$ have convulsions if, in addition, blood urea level exceeds $90 \mathrm{mg} / 100 \mathrm{ml}$. These may contribute to permanent brain damage and are less likely to occur if plasma osmolality is reduced slowly and rehydration is gradual.

The mother of our patient found that she could only satisfy the child's 'hunger' by greatly increasing the amount of milk powder per feed. The milk that she made up contained $86 \mathrm{mEq} / \mathrm{l}$. sodium, osmolality $1103 \mathrm{mOsm} / \mathrm{kg}$, the normal values being respectively $26 \mathrm{mEq} / \mathrm{l}$. and $315 \mathrm{mOsm} / \mathrm{kg}$. Such a high solute load will stimulate thirst but if the demands of the child are met with further highly concentrated feeds, more solute than fluid is received and a vicious cycle is set up. Hot weather may have been an important contributory factor in our patient.

It would perhaps be wise for the manufacturers' instructions on tins of powdered milk to contain a warning about the dangers of exceeding the recommended concentration.

\section{Summary}

A 9-month-old infant, admitted to hospital in coma due to hyperosmolar dehydration, was slowly rehydrated over a period of 10 days. Neurological recovery, though slow and interrupted in the second week by the transient appearance of choreoathetoid movements, was complete after 5 weeks.

A regimen of gradual rehydration and slow reduction in plasma osmolality may minimize the considerable risk of fits and permanent brain damage attendant upon this condition.

This child's condition apparently resulted from the injudicious use of highly concentrated milk feeds during a bout of hot weather when increased insensible fluid losses were not replaced.

We wish to thank Dr. L. Stimmler for permission to publish this case and for his helpful criticism.
REFERENCES

Cochrane, W. A. (1965). Overnutrition in prenatal and neonatal life: a problem? Canadian Medical Association fournal, 93, 893.

Colle, E., Ayoub, E., and Raile, R. (1958). Hypertonic dehydration (hypernatremia): the role of feedings high in solutes. Pediatrics, 22, 5 .

Darrow, D. C. (1959). The significance of body size. American Fournal of Diseases of Children, 98, 416.

Finberg, L., and Harrison, H. E. (1955). Hypernatremia in infants : an evaluation of the clinical and biochemical findings accompanying this state. Pediatrics, 16, 1.

Macaulay, D., and Watson, M. (1967). Hypernatraemia in infants as a cause of brain damage. Archives of Disease in Childhood, 42, 485.

Morris-Jones, P. H., Houston, I. B., and Evans, R. C. (1967). Prognosis of the neurological complications of acute hypernatraemia. Lancet, 2, 1385.

Simpson, H., and O'Duffy, J. (1967). Need for clarity in infant feeding instructions. British Medical fournal, 3, 536.

Skinner, A. L. (1967). Water depletion associated with improperly constituted powdered milk formulas. Pediatrics, 39, 625 .

Taitz, L. S. (1971). Infantile overnutrition among artificially fed infants in the Sheffield region. British Medical fournal, 1, 315.

G. M. STERN, ^ R. B. Jones, $†$ and A. C. L. Fraser Evelina Children's Hospital, Guy's Hospital, London SE1.

^Correspondence to Dr. G. M. Stern, Poole General Hospital, Poole, Dorset BH15 2JB.

tPresent address: Wolfson Institute, London WC1, and The Hospital for Sick Children, Great Ormond Street, London WC1.

\section{Congenital Hypothyroidism and Neonatal Jaundice}

The association between congenital hypothyroidism and jaundice in the neonatal period has been recognized for some years (Åkerrén, 1954; Christensen, 1956) and is mentioned in reviews of neonatal jaundice and in textbooks. None the less it is the authors' experience that few paediatricians think of this diagnosis unless other obvious features of hypothyroidism are present in a jaundiced baby.

This paper reports 12 babies with significant hyperbilirubinaemia which was apparently caused by hypothyroidism. 4 of these babies were referred to one author for diagnosis of neonatal jaundice, 6 additional cases were found by searching the case notes of 56 babies and children with hypothyroidism seen at the Royal Children's Hospital, Melbourne, in the period 1960-70, and 2 were diagnosed by another paediatrician in Melbourne.

Only 18 of the 56 case histories reviewed contained a statement regarding neonatal jaundice. Neonatal jaundice had been the presenting feature in 4 babies (including 3 of those diagnosed by the 